\title{
Research on the Ideological and Political Education Mode under the Internet and Media Era
}

\author{
Lin Wang ${ }^{1,}$ \\ ${ }^{1}$ ChongQing College of Electronic Engineering, China.
}

Keywords: Internet and Media; Ideological and Political; Education; Mode; Colleges.

\begin{abstract}
This paper conducts the research on the ideological and political education mode under the Internet and media era. Adhere to the dominant is the essence of the ideological and the political education of human practice activities. The sustainable development of human being is put forward according to the drawbacks of the traditional education. In the new historical period of continuing to promote great cause of socialism with Chinese characteristics, we should actively learn from this basic experience and as closely integrate with the new historical conditions and give full play to the political advantages of ideological and political education. The proposed methodology can promote the further development of the college ideological and political education.
\end{abstract}

\section{Introduction}

Ideological and political education refers to the social or social groups with a certain ideological concepts, political views and moral norms of its members to exert a purpose, planned, organized influence, so that they meet the social requirements of qualified ideological and political character of knowledge and practice one of the activities. Ideological and political education is the main direction of ideological and political education to guide chooses the main direction, aspects and focus, and in the individual development and social development plays a leading role. On its essence, it is to adhere to a certain social ideology and the social dominant value orientation. Adhere to the dominant is the essence of the ideological and the political education of human practice activities. The sustainable development of human being is put forward according to the drawbacks of the traditional education such as exam-oriented education and one-sided education, which should be realized through quality education and human's sustainable development is also pursuit of quality education. The sustainable development of ideological and political education is aimed at the traditional ideological and political education which can be discussed from the listed aspects.

- The economic value of the ideological and political education of college students is mainly embodied in the ideological and political education, so that students clearly the purpose of the learning, learning motivation, in order to engage in socialist economic construction must have the necessary knowledge and skills.

- Political value of modern college moral education mainly displays, through ideological and political education, guides the university student development and understanding society, the firm and correct the political orientation and political stand, strengthen the democracy and legal system consciousness.

- The cultural value of the ideological and that political education of college students mainly includes through ideological and political education to promote the absorption and inheritance of the outstanding traditional culture of the Chinese nation, to learn from Western culture and critical transformation. At the same time, based on the construction of campus culture, the mainstream culture of socialism, patriotism, collectivism and other social mainstream culture can be infiltrated into this sub culture.

With the rapid development of information technology, the network has affected college students thinking, ideas, values, thinking, psychology and many other important aspects. It can be said that the network is university student lives, works to a certain extent and studies one of the essential contents, therefore in carrying on spirit education for college students process, the network gradually becomes the spirit education for college students new position has provided the opportunity and platform for 
the transformation and the innovation of spirit education for college students work. In the following figure one, we show the reflections of the Internet and media era.

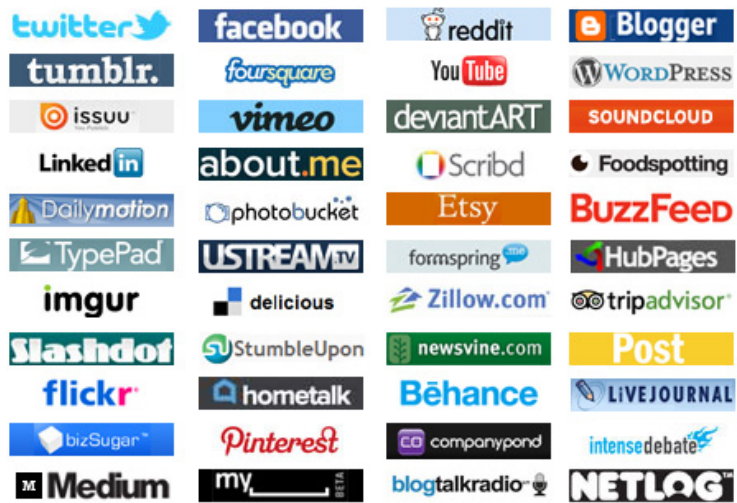

Fig. 1 The Reflections of the Internet and Media Era

Under this basis, this paper integrates the current condition to propose the ideological and political education mode under the Internet and media era. We will discuss in detail later.

\section{The Proposed Methodology}

\subsection{The Internet and Massive Media Principles.}

The rich media generation is to refer to having video, audio frequency, image, text, animation and the other rich media as well as the interactivity information dissemination way. The rich media and biggest difference of conventional media technology is: the multimedia applications do not have the interactivity generally, but the rich media actually increased the interactivity concept as improves the percentage participating of audience and thus improves the user experience. Based on the literature review, the technologies of the massive media can be organized as follows.

1) LASeR. The LASeR goal is to complete the rich media service of all description ranks. The LASeR standard indicated including the SVG scenarios tree that the LASeR scenarios tree expands, dynamic updating, dual code, sound video support, the use of typeface information, as well as the scene increase service. Both the LASeR and SVG are allowed to embed font information in the scene. Because MPEG think that SVG font solution is too limited, it is recommended that the font information and scene information as a media stream.

2) SAF. The task of the SAF is to complete the rich media services for all interfaces between the media/scene description and the existing transport protocols. SAF streams can be sent using any sending mechanism: download, progressive download, streaming, or broadcast. SAF defines a binary representation of a mixed data stream, including LASeR scene descriptions, audio and video, images, fonts, metadata streams, and a SAF stream that mixes the content for simple, efficient, and the final synchronous delivery.

\subsection{The Internet and the Ideological and Political Education.}

The connotation of network ideological education here mentioned in fact had two understanding: First, ideological education under network environment; while second, the ideological education of web-based. Looking from practice specific of network ideological education, the issues that above two understanding involve interwines mutually that looking from fundamental research of network ideological education, above two understanding are in different levels, the generalized understanding of network ideological education is the basis and prerequisite of narrow understanding. The network provides equal opportunities for people to exchange ideas, to realize the equality of education and the teachers in the network at both ends of the disappeared under the traditional education information advantage and experience advantage, as the authority in front of the students can not break the original classification method of information communication.

Based on the SWOT analysis, we summarize the features of the Internet based education as the follows. (1) Strengths. Network can integrate the main force of ideological and political education, and constantly expand the scope of the main body of Ideological and political education in colleges and universities. Network during integrated ideological and political education main force, but can 
also conform that various ideological and political education resources making the content of spirit education for the college students richer. Through the network, the university student can anytime and anywhere with other people exchange idea, the free input and gain related education content, the consult study material that understands in the world various social phenomena, the ideas and cultural ideological trend. (2) Weaknesses. The development of network to the authoritative resources of the education was conducted has redistributed, the teacher no longer was the absolute information source, the university student beyond example strengthens to the selectivity of some information, tended to believing own independent judgment. At present, network of colleges and universities, ideological and political "amphibious expert" team is still scarce while the network ideological and political team composition is not reasonable, part-time combination of general stable campus network construction, maintenance, publicity and that commentary team has not been established. (3) Opportunities. The research of network ideological and political education constantly deepens, instills the power for the university network ideological and political education unceasingly. The educational world to the inside and outside environment, opportunities and challenge, the work content, method and method that network ideology and strengthen faces, as well as the Internet culture, the Internet public opinion and network thought of the long-term mechanism of political education to conduct the research of the varying degrees, advanced the university network to think of the development of political educational work effectively. (4) Threats. The virtual nature of the network causes college students not to face the difficulties and setbacks of real life actively, and they hope to seek the perfect life in the virtual world. The direct consequence of being addicted to the network is to replace "interpersonal communication" with "human-computer interaction", to alienate the family and the friends of teachers, students, and friends who are close at hand while neglecting face-to-face communication.

In the era of the network to give full play to the advantages of network communication, not simply the traditional ideological and political education model transplanted to the Internet, but focus on the actual situation of colleges and universities, carefully designed site positioning site construction scale, targeted and attractive of the channel and other columns. In addition, fully adept and has innovative ideology and other characteristics using the university student computer operation skill, with the aid of the network resource, leading the student to manufacture the homepage and project approach, to establish the technical website, actively launches the online technological activities will exercise the ability and practice operation of the ability student builds the good foundation for the student future multi-superiority development, will carry out the colorful and spirited online exchange will develop the friendly ideological nature and knowledgeable, interesting as one online campus culture activities.

\subsection{Ideological and Political Education Suggestions.}

It is an essential component of the applied research in the field of the ideological and the political education. It is the essential requirement to further strengthen and improve the ideological and the political education of college students. It exists in the whole process of college students' ideological and the political education, which as the ideological and political education of college students and the vitality of education. Indeed, seeped in ideological and political education to each level of social life immediately, the economic function, the cultural function, the ecological function ideological and political education the non-ideological functions have become more and more important and essential prominent which is looking after aspect to the person survival condition, the ideological and political education is playing the more and more vital role in promotion personality the freedom full scale development of promotion and person of perfect and mental outlook. The connotation of ideological and political education of college students in scientific outlook on development, scientific outlook on development as the basic guiding principle of ideological and political education, the overall planning of the ideological and political education into the economic and social development, into the reform and development of the university, academic construction and professional construction, therefore, we provide the following suggestions based on the figure two.

- When people recognize their own subjective position, recognizing the constant creation is the responsibility of every social person, it will take responsibility for the creation and create the passion of creation while showing the pursuit of creative action. 
- Tenacious and will becomes most important personality that helps creating. The ideological and political education through helping people development personally to the responsibility of society, through strengthening the correct philosophy and values education, guides the people development creation regarding the value of significance and own life of nationality.

- In the creative activities, creative thinking is the core factors to create results and most of the necessary, all the human achievements in essence is nothing but the creative thinking is the thinking and material, the higher the quality, creativity is stronger, and the quality of thinking and to a great extent depends on the mode of thinking whether science.

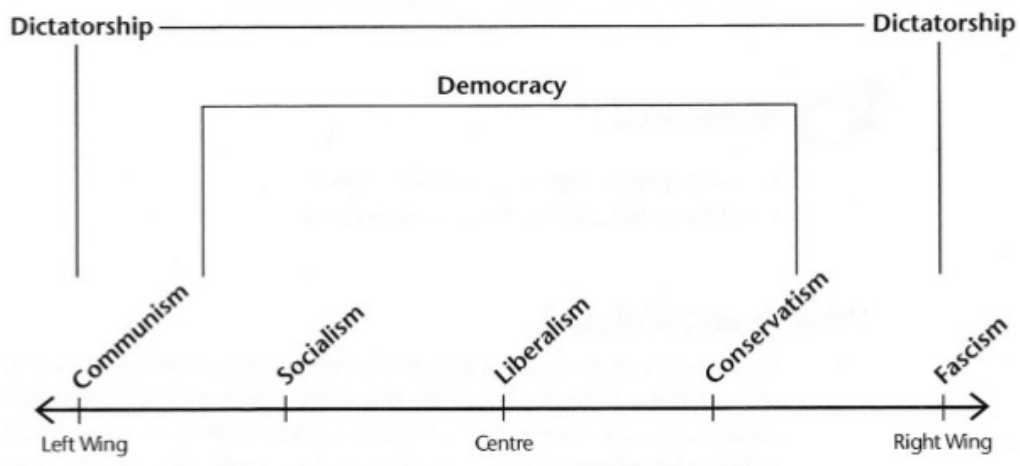

Fig. 2 The Novel Framework of the Ideological and Political Education

\section{Summary}

This paper conducts the research on the ideological and political education mode under the Internet and the media era. History shows that the importance of lifeline status of the ideological and political education, is an important magic weapon for the great victory of China's revolution, construction and reform give full play to guide the ideological and political education of the masses and other work to ensure the service and role of ideological and political education is the most basic experience. In the new historical period of continuing to promote great cause of socialism with Chinese characteristics, we should actively learn from this basic experience and as closely integrate with the new historical conditions and give full play to the political advantages of ideological and political education. We integrate the Internet and media era to propose the ideological and political education mode that will then promote the further development of the related theories and methodologies.

\section{References}

[1]. Yang, M. E. N. G. "People-Oriented: New Concept for Ideological and Political Education Management in University." Journal of Taiyuan Normal University (Social Science Edition) 2 (2014): 031.

[2]. He, Lin Zhi. "Innovation analysis of the ideological and political education reform in Colleges and Universities under the new media environment." 2015 International Conference on Education Technology, Management and Humanities Science (ETMHS 2015). Atlantis Press.

[3]. Xia, W. U. "Review and Prospects of the Impact of Social Environment on Ideological and Political Education." Higher Education of Social Science 8.1 (2015): 52-59.

[4]. Zhengping, He, and Shi Peng. "Study on the Characteristics of Vietnamese University's Ideological and Political Education." Around Southeast Asia 8 (2013): 004. 